\title{
Undergraduate Nursing Students' and Clinical Instructors' Perceptions of the Characteristics of an Effective Clinical Instructor at the Faculty of Nursing, Cairo University
}

\author{
Sahar Hassan Aly EL Banan ${ }^{1}$, Nadia Bassuoni Elsharkawy ${ }^{2}$ \\ ${ }^{1}$ Department of Nursing Administration, Faculty of Nursing, Cairo University, Cairo, Egypt \\ ${ }^{2}$ Department of Maternal and Newborn Health Nursing, Faculty of Nursing, Cairo University, Cairo, Egypt
}

Email address:

sherif.tours@yahoo.com (S. H. A. EL Banan), nadiabassuoni@yahoo.com (N. B. Elsharkawy)

To cite this article:

Sahar Hassan Aly EL Banan, Nadia Bassuoni Elsharkawy. Undergraduate Nursing Students' and Clinical Instructors' Perceptions of the Characteristics of an Effective Clinical Instructor at the Faculty of Nursing, Cairo University. American Journal of Nursing Science. Vol. 6, No. 3, 2017, pp. 185-192. doi: 10.11648/j.ajns.20170603.16

Received: February 23, 2017; Accepted: March 9, 2017; Published: March 23, 2017

\begin{abstract}
Learning in the clinical environment is an essential part of nursing education programs. Effective clinical teaching is crucial for the learning of nursing students in the clinical settings. It helps in preparing students for the work they will have to do as practicing nurses [1]. The study aimed to identify the undergraduate nursing students' and clinical instructors' perceptions of the characteristics of an effective clinical instructor at the Faculty of Nursing- Cairo University. A descriptive cross- sectional design was utilized of the study. This study was conducted at the Faculty of Nursing, Cairo University. A convenience sample of (591) nursing students and (112) clinical instructors who are working at the Faculty of Nursing- Cairo University and are willing to participate in the study. The Nursing Clinical Teacher Effective Inventory (NCTEI) was used for data collection. Results indicated that the categories of teaching ability and interpersonal relationships were the most valued characteristics rated by both undergraduate nursing students and clinical instructors. While, the least valued characteristics rated by both undergraduate nursing students and clinical instructors were the categories of nursing competence, personality traits and evaluation. The study recommended that workshops/seminars should be organized to orient clinical teachers on their roles in clinical setting. Periodic clinical instructors' evaluation is necessary to incorporate unused behaviors, into their practice.
\end{abstract}

Keywords: Clinical Instructor, Clinical Instruction, Clinical education

\section{Introduction}

Nursing is one of the difficult jobs that offer services to healthy and sick people in different sectors by using specific knowledge and skills. Nursing students require learning clinical skills in addition to acquisition of knowledge during their training; therefore, nursing is a practical profession and clinical training constitutes the majority of its nursing student's educational courses [2]. Quality of clinical education of nursing students had been determined as one of the most important factors affecting the quality of nursing education. So, it is called the heart of the education of professional nursing 34

Learning in the clinical environment is an essential part of nursing education programs. Effective clinical teaching is crucial for the learning of nursing students in the clinical settings [1]. Clinical teaching helps in preparing students for the work they will have to do as practicing nurses. Furthermore, clinical experience allows nursing students to participate actively in the healthcare team, demand solutions to real life problems and learn by doing while caring for patients, thereby they are becoming competent practitioners [5]. A poorly trained nurse might hinder the team's effectiveness leading to ineffective nursing care. Studies have shown that effective clinical instructor behaviors promote effective clinical teaching which in-turn improves students' learning process $[6,7,8]$.

Clinical teaching is a group of planned experiences designed to assist nursing students in acquiring skills, attitudes and knowledge by participating in the work setting. 
It is considered as essential and very important part of professional nursing education. Since nursing is a discipline based on practice, it needs to be curriculum of education that offers students the opportunity to develop their clinical skills. The clinical instruction is one of the most significant parts of the educational process, because the majority of the learning process is completed in a clinical setting. More than $50 \%$ of nursing student's time is spent in clinical practice which has an essential role in formulating and learning of their professional values, norms and attitudes. The clinical instructor is an integral part of a quality clinical experience as well as charged with the task of aiding the student in transferring knowledge learned in the classroom to implementation at the bedside $[9,10,11]$.

Clinical instruction is an essential part in programming, and gaining clinical experience which is the fundamental element in providing convenient conditions for the attainment of clinical education, because it can recompense the shortcomings and deficiencies of educational institutions $[12,13]$. Clinical education, in spite of the profession or setting, is a process that had been studied from both the instructor and student points of view to identify the best practices [14]. Clinical education is used across many health care professions as a way to practice instructional information in a clinical training environment. The goal of clinical education is to combine theory and practice in a controlled clinical learning environment to supply students with learning that has the adequate skills, behaviors and attitudes that is important for entry into professional practice [15].

Clinical instructor works supportively by offering his/her experiences and suitable corrective feedback to the students and by active presence as a source of confidence, courage, restoring order and discipline. $\mathrm{He} / \mathrm{she}$ is also a factor for setting effective communication between student and patient, student and physician, causing taking responsibility and effective learning of academic and clinical skills of trainees, as well as the reduction of fear and anxiety [16]. Therefore, improper clinical instructor preparation is seen as a major problem to effective clinical teaching. Effective clinical teaching is vital for the quality nursing practice and that nursing students experiences of their clinical practice provide greater insight for the development of an effective clinical teaching strategy [13]. On the other hand, students can also evaluate his/her strengths and weaknesses from various perspectives of science, morality and behavior [17].

[18] reported that in order to prepare nursing students for the role of professional nursing, nursing education programs must provide clinical experience alongside with theoretical knowledge. Student involvement in clinical practice is often the most important part for acquiring new nursing skills. [19, 20] added that the primary goal of nursing education is assisting nursing students in the development of competent practicing nurses. Therefore, clinical instructors must be effective to provide the best learning experiences in each clinical situation. Clinical instructor characteristics that have a positive effect on the outcomes of students must be identified and utilized. Exploration of the characteristics of effective clinical instructors expands the insight of educational institutions for improvement of educational programs. Clinical instructor effectiveness has an impact on nursing students learning outcomes. The relationship between nursing students and instructors is important to increase the satisfaction and competence of nursing students learning process.

As the nursing schools are always trying to improve their educational plans, and these plans are based on this assumption that courses and teaching atmosphere, train competency and efficiency in different aspects of theory and practice, and as the students as consumers of educational services have direct and straightforward connection with this process grow, they are the best source for detection of clinical education problems. Also from the previous review of literatures, there is a major area of research on studentinstructor relationship has emerged as important to the clinical education of nursing students. This area is related to nursing students' and clinical instructors' perceptions of the characteristics an effective clinical instructor. So this study was done to identify the undergraduate nursing students' and clinical Instructors' perceptions of the characteristics of an effective clinical instructor.

\subsection{Significance of the Study}

The clinical component of nursing education is a significant part in the development of competent nurses. Clinical instructors have an important role in the development of professional nursing students. Identification of the characteristics of effective clinical instructors provides useful information for student instruction in the clinical setting and is essential for improving the quality of clinical education [10].

Clinical instructors have a critical role in the education and development of nursing students. They are responsible for ensuring student learning while acquiring clinical training experience to practice techniques. At the same time, instructors are responsible for ensuring that patients receive high quality and safe nursing care $[21,22]$. Investigation of the characteristics of an effective clinical instructor provides insight into improvement of educational programs for developing nurses. For these reasons, it is pressing that clinical instructors have the skills and strategies to make clinical experiences conducive to learning and patient safety and it is useful to identify the characteristics that lead to highly effective skills and techniques [23].

Through reviewing literatures, it was observed that most of studies focused on the characteristics of the clinical instructor from the perspectives of nursing students, with few studies examining clinical instructor's opinion about clinical effectiveness. Student's perceptions of the characteristics of an effective clinical instructor are important indicators to change and facilitate effective clinical instruction. Results of the present study may assist clinical instructors to value students' perceptions and compare it with their own perceptions. Consequently, they may become conscious of 
those characteristics of success to reinforce them, as well as those that need improvement. Also, the results of this study would identify the characteristics which are important for clinical instructor that could help the students achieve their desired goals. Therefore, it is important that clinical instructors should identify and incorporate effective teaching characteristics in their clinical teaching and thus potentially enhance student learning in clinical settings. Therefore, they contribute to knowledge in nursing education regarding the characteristics of effective clinical instructor and may assist programs in mentoring and training new clinical instructors.

\subsection{Aim of the Study}

The aim of this study was to identify the undergraduate nursing students' and clinical instructors' perceptions of the characteristics of an effective clinical instructor at the Faculty of Nursing, Cairo University.

\subsection{Research Questions}

(1) What are the undergraduate nursing students' perceptions of the characteristics of an effective clinical instructor?

(2) What are the clinical instructors' perceptions of the characteristics of an effective clinical instructor?

(3) Is there a difference between undergraduate nursing students' and clinical instructors' perceptions of the characteristics of an effective clinical instructor?

\section{Subjects and Methods}

\subsection{Design}

A descriptive cross- sectional design was used to achieve the aim of this study.

\subsection{Setting}

The study was carried out at the Faculty of Nursing, Cairo University.

\subsection{Sample}

A convenience sample of (591) nursing students and (112) clinical instructors who are working at the Faculty of Nursing, Cairo University and who are willing to participate in the study; nursing students from different academic levels of baccalaureate nursing programs at faculty of nursing, Cairo University who had finished at least two clinical rotations with patient care in hospital and willing to participate in the study were recruited. The students in first academic level excluded because they don't have clinical training experience to identify characteristics of effective clinical instructor. Clinical instructors and students number represents the majority of clinical instructors working in the faculty and the majority of students in each level.

\subsection{Tool}

The study utilized the Nursing Clinical Teacher
Effectiveness Inventory (NCTEI) developed by Knox and Mogan (1985) [24] to measure respondents' perceptions of 47 items. The tool divided into five subsets of clinical teacher characteristics: (a) Interpersonal relationship (11 items) refers to the relationship between students and the instructor that enhances the educational experience [25]. (b) Personality traits ( 7 items) are the emotional tendencies and character traits that include the ability to control their temper and exhibit patience, treat students sincerely, show empathy toward students, and have an enthusiastic attitude in clinical teaching [21]. (c) Teaching ability (13 items) is the process of transmission of skills and attitudes; the creation of an environment that enables learning [26]. It includes instructional skills, creating a positive learning environment, and promoting learning [25], (d) Nursing competence (9 items) is the clinical instructor's theoretical and clinical knowledge used during practice, including the instructor's attitude toward the profession [27] and (e) Evaluation (7 items) is the type and amount of feedback the student receives from the teacher in relation to clinical performances and written assignments. It includes providing timely feedback, providing constructive criticism, and praise for work done well. Respondents rate their responses of each characteristic on a five-point Likert-type scale ranging from" 1 " strongly disagree and " 5 " strongly agree. The tool was tested for reliability with subset coefficients ranging from.82 to.89. Alpha coefficients also were obtained by Knox and Mogan (1987)[28] of the sub-scales: Interpersonal relationships, $\alpha=.86$; Personality traits, $\alpha=.83$ Teaching abilities, $\alpha=.89$; Nursing competence, $\alpha=.84$ and Evaluation, $\alpha=.82$

\subsection{Content Validity of the Arabic Version of the Tool}

A tool was translated into Arabic version by researchers, and then handed to a group of four experts in Nursing Administration and Maternal \& Newborn Health Nursing, one professor and three assistant professors from the Faculty of Nursing Cairo, University to assess the coverage, relevancy and clarity of items. Based on their recommendations, the necessary modifications were made.

\subsection{The Pilot Study}

A pilot study was conducted to test the clarity and applicability of the questionnaire and to estimate the time needed to fill the questionnaire. Based on the pilot study analysis no modifications were done in the questionnaire and the time consumed ranged between 15 to 20 minutes. Undergraduate nursing students and clinical instructors participated in the pilot study included in the study sample.

\subsection{Ethical Consideration}

An official permission was gained from dean of the faculty and each department chairperson. Consent was obtained from each student as well as clinical instructor after verbal explanation of the nature and the purpose of the study. Clinical instructors and nursing students were acquainted that their participation in the study is voluntary and informed that 
their responses will be confidential and used only for the research purpose.

\subsection{Procedure}

The researcher fully explained the purpose, nature, and significance of the study for every respondent (students and clinical instructors) to obtain their acceptance to participate in the study and to the department chairpersons to get better cooperation during the implementation phase of the research. The questionnaire was handed to the clinical instructors while they were on duty and to the nursing students during their classes' time. The way of answering was explained to them. The time consumed to fill the questionnaires ranged from 15 to 20 minutes. Data were collected during 2016 with duration of four months (April to July).

\subsection{Statistical Analysis}

Data entry and statistical analysis were performed using the statistical package for social studies (SPSS), version 20. Suitable descriptive statistics were used such as frequencies, and percentages for qualitative variables, means, and standards deviations for quantitative variables.

\section{Results}

Table 1 represents personal characteristics of an undergraduate nursing students participated in the study. It shows that the majority of the participants $(78.2 \%)$ had more than 20 years and the majority of them $(72.6 \%)$ were female. Students selected from three different academic levels, second level, third level and fourth level $(45 \%, 25.7 \%$ \& $29.3 \%$ respectively).

Table 1. Distribution of undergraduate nursing students by their personal characteristics $(N=591)$.

\begin{tabular}{lll}
\hline Demographic Characteristics & Frequency & \% \\
\hline Age: & & \\
$<18$ & 4 & 0.7 \\
$18-20$ & 125 & 21.1 \\
$\geq 20$ & 462 & 78.2 \\
Gender: & & \\
Male & 162 & 27.4 \\
Female & 429 & 72.6 \\
Academic Level & & \\
Second & 266 & 45 \\
Third & 152 & 25.7 \\
Fourth & 173 & 29.3 \\
\hline
\end{tabular}

Table 2 represents personal characteristics of clinical instructors participated in the study. It reveals that majority of participants $(75.9 \%)$ had from 25 years to less than 30 years and the highest percentages of them $(82.1 \%)$ were female. The highest percentages of participants $(82.1 \%)$ had a master degree and about half of them had less than five years of experience.

Table 2. Distribution of clinical instructors by their personal Characteristics $(N=112)$.

\begin{tabular}{lll}
\hline Personal Characteristics & Frequency & $\mathbf{\%}$ \\
\hline Age: & 6 & \\
$<25$ & 6 & 5.4 \\
$25-30$ & 85 & 75.9 \\
$30-34$ & 11 & 9.8 \\
$\geq 35$ & 10 & 8.9 \\
Gender: & & \\
Male & 20 & 17.9 \\
Female & 92 & 82.1 \\
Educational Level: & & \\
Baccalaureate degree & 29 & 17.9 \\
Master degree & 83 & 82.1 \\
Years of experience: & & \\
$<5$ & 51 & 45.5 \\
$5-10$ & 48 & 42.9 \\
$\geq 10$ & 13 & 11.6 \\
\hline
\end{tabular}

Table 3 shows the descriptive statistics of nursing students' perceptions of the characteristics of effective clinical instructor by category. As shown, the highest category mean score was teaching ability followed by interpersonal relationship (23.69 \& 21.69) respectively. Nursing competence, personality traits and evaluation were the lowest scored categories (15.99, 13.25\& 13.20) respectively.

Table 3. Descriptive statistics of undergraduate nursing students' perceptions of the characteristics of effective clinical instructor by category $(N=591)$

\begin{tabular}{llll}
\hline Effective Clinical Instructor Subscales & Min & Max & Mean \pm SD \\
\hline Teaching Ability. (13 items) & 13 & 61 & $23.69 \pm 9.95$ \\
Interpersonal Relationships. (11 items) & 11 & 53 & $21.69 \pm 7.71$ \\
Nursing Competence. (9 items) & 9 & 43 & $15.99 \pm 7.16$ \\
Personality Traits. (7 items) & 7 & 33 & $13.25 \pm 5.81$ \\
Evaluation. (7 items) & 7 & 35 & $13.20 \pm 6.47$ \\
Total: & 47 & 225 & $87.82 \pm 37.1$ \\
\hline
\end{tabular}

Table 4 shows the descriptive statistics of clinical instructors' perceptions of the characteristics of effective clinical instructor by category. As shown, the highest category mean score was teaching ability followed by interpersonal relationship (20.77 \& 18.71) respectively. Nursing competence, personality traits and evaluation were the lowest scored categories $(15.02,11.96, \& 11.29)$ respectively.

Table 4. Descriptive statistics of clinical instructors' perceptions of the characteristics of effective clinical instructor by category $(N=112)$.

\begin{tabular}{llll}
\hline Effective Clinical Teacher Subscales & Min & Max & Mean \pm SD \\
\hline Teaching Ability. (13 items) & 13 & 39 & $20.77 \pm 6.60$ \\
Interpersonal Relationships. (11 items) & 11 & 36 & $18.71 \pm 5.71$ \\
Nursing Competence. (9 items) & 9 & 37 & $15.02 \pm 5.66$ \\
Personality Traits. (7 items) & 7 & 24 & $11.96 \pm 4.29$ \\
Evaluation. (7 items) & 7 & 35 & $11.29 \pm 5.00$ \\
Total: & 47 & 171 & $77.75 \pm 27.26$ \\
\hline
\end{tabular}

Table 5 represents the rank order of the ten important 
characteristics of an effective clinical instructor as perceived by nursing students. The following characteristics highly perceived by undergraduate nursing students as the top characteristics of an effective clinical instructor: Demonstrates flexibility in dealing with students, demonstrates genuine interest in patients and their care, questions students to elicit understanding, communicates knowledge to students, demonstrates a willingness to help, displays confidence in ability as a professional nurse, stimulates students' interest in the subject, allows student an opportunity to practice before evaluating, clinical assignments relate to course objectives and makes continuous evaluation. (90.9\%, 90.2\%, 89.2\%, 88.7\%, 88.3\%, 87.3\%, $86.5 \%, 86.1 \%, 86$ and $85.4 \%$ ) respectively.

Table 5. Rank order of the ten important characteristics of an effective clinical instructor as perceived by undergraduate nursing students $(N=591)$.

\begin{tabular}{lll}
\hline Characteristics of Effective Clinical Teacher & NO & $\mathbf{\%}$ \\
\hline 1. Demonstrates flexibility in dealing with students. (PT) & 537 & 90.9 \\
2. Demonstrates genuine interest in patients and their care. & 533 & 90.2 \\
(TA) & & \\
3. Questions students to elicit understanding. (TA) & 527 & 89.2 \\
4. Communicates knowledge to students. (NC) & 524 & 88.7 \\
5. Demonstrates a willingness to help. (NC) & 522 & 88.3 \\
6. Displays confidence in ability as a professional nurse. & 516 & 87.3 \\
(NC) & & \\
7. Stimulates students' interest in the subject. (TA) & 511 & 86.5 \\
8. Allows student an opportunity to practice before & 509 & 86.1 \\
evaluating. (E) & & \\
9. Clinical assignments relate to course objectives. (TA) & 508 & 86 \\
10. Makes continuous evaluation. (E) & 505 & 85.4 \\
\hline
\end{tabular}

Note. Personality Traits (PT), Teaching Ability (TA), Nursing Competence (NC), Evaluation (E)

Table 6 reveals rank order of the ten important characteristics of an effective clinical instructor as perceived by clinical instructors. The following characteristics highly perceived by clinical instructors as the top characteristics of an effective clinical instructor: Helps students identify and make use of practice opportunities, demonstrates open and honest communication with students, presents a neat appearance, clinical assignments relate to course objectives, provides appropriate and timely feedback, stimulates students' interest in the subject, encourage active participation in group discussion, is organized, demonstrates a willingness to help and gives credit for a job well done. (98.2\%, 97.3\%, 96.4\%, 96.4\%, 96.4\%, 96.4\%, 95.5\%, $95.5 \%, 95.5 \%$ and $94.6 \%$ ) respectively.

Table 6. Rank order of the ten important characteristics of effective clinical instructor as perceived by clinical instructors $(N=112)$.

\begin{tabular}{lcc}
\hline Characteristics of Effective Clinical Teacher & NO & \% \\
\hline $\begin{array}{l}\text { 1. Helps students identify and make use of practice } \\
\text { opportunities. (TA) }\end{array}$ & 110 & 98.2 \\
$\begin{array}{l}\text { 2. Demonstrates open and honest communication with } \\
\text { students. (IR) }\end{array}$ & 109 & 97.3 \\
3. Presents a neat appearance. (PT) & 108 & 96.4 \\
4. Clinical assignments relate to course objectives. (TA) & 108 & 96.4 \\
5. Provides appropriate and timely feedback. (TA) & 108 & 96.4 \\
6. Stimulates students' interest in the subject. (TA) & 108 & 96.4 \\
7. Encourage active participation in group discussion. (TA) & 107 & 95.5 \\
8. Is organized. (PT) & 107 & 95.5 \\
\hline
\end{tabular}

\begin{tabular}{lll}
\hline Characteristics of Effective Clinical Teacher & NO & $\mathbf{\%}$ \\
\hline 9. Demonstrates a willingness to help. (NC) & 107 & 95.5 \\
10. Gives credit for a job well done. (E) & 106 & 94.6 \\
\hline
\end{tabular}

Note. Teaching Ability (TA), Interpersonal Relationship (IR), Personality Traits (PT), Nursing Competence (NC), Evaluation (E).

\section{Discussion}

Teaching and learning are casually tight bound activities. Clinical teaching is the heart of nursing educational program and remains the single most important resource in the development of competent, capable and caring nurses. Identifying clinical teaching characteristics of teaching faculty is essential in order to improve clinical skills of nursing students [29]. Clinical teaching is the essence of all nursing education because clinical education is the way by which clinical instructors facilitate nursing students to acquire knowledge and skills in the real practical setting to become competent and skilled nurses. Clinical Faculty plays an important role because they provide students with an opportunity to achieve competency, self confidence, professional identity, professional attitudes, and proficiency in their profession $[30,22]$. The results of the present study aimed to identify the undergraduate nursing students' and clinical instructors' perceptions of the characteristics of an effective clinical instructor at the Faculty of Nursing- Cairo University.

[25] stated that an effective teacher must have mastered the ability to teach. This ability includes the skills required to transmit knowledge, skills, and attitudes from the teacher to the student and also included the ability to develop an atmosphere that encourages student learning. The findings of the present study revealed that clinical teaching ability of the clinical instructors was the first important effective clinical teaching characteristic as perceived by the undergraduate nursing students and clinical instructors. This is may be due to nursing students' feelings of security as a result of being with a knowledgeable and skilled clinical instructor who acts as a facilitator in the clinical setting. This result is congruent with a study of [10] entitled (Caring and effective teaching behavior of clinical nursing instructors in clinical area as perceived by their students) whose research findings indicated that teaching ability was valued by nursing students as the important effective clinical teaching characteristic. This result is also in alignment with the previous studies of $[31,32]$ whose results indicated that clinical instructors' teaching ability was rated as the most important characteristic as perceived by their students. While this result was inconsistent with the result of [33] who stated that teaching ability was rated by nursing students as the lowest characteristic of clinical teacher and valued by educators as the most important characteristic of clinical instructor.

As regards the interpersonal relationships, the results of the present study indicated that clinical instructors' interpersonal relationships was valued as the second important effective clinical teaching characteristic as perceived by the undergraduate nursing students and clinical instructors. This result is in agreement with the results of 
[27], which indicated that the category of interpersonal relationships was the most highly valued characteristic rated by both Australian students and clinical educators. Also, this result is in alignment with the results of $[33,13]$ that showed interpersonal relationship as the most valued characteristic of clinical instructor. In addition, in a research study on the effective characteristics of clinical instructors, interpersonal relationships was the category that accounted for the largest difference between effective and ineffective clinical instructors $[34,35]$. On the other hand, these results were inconsistent with the results of [20] whose results indicated that teaching ability of the clinical instructor was rated by clinical instructors as the lowest category of the characteristics of effective clinical instructor.

Furthermore, the results of the present study revealed that nursing competence, personality traits and evaluation perceived as the lowest characteristics of effective clinical instructor by both the undergraduate nursing students and clinical instructors. These results were congruent with the results of [13] which indicated that the lowest score of an effective clinical instructor has been assigned to the evaluation feature. In addition, in a study done by [20] revealed that personality traits and evaluation categories were rated as the lowest categories of clinical instructor characteristics by nursing students and evaluation category was rated as the lowest characteristic of clinical instructor. Also this result was in alignment with the result of [27] that indicated personality traits was rated by Australian students and clinical educators as the lowest category amongst five categories.

[36] pointed that, the clinical environment stops being an area of learning and after a short time becomes just a place where the student to graded. How the demonstrator evaluates the student in the clinical environment and how she gives feedback is an important aspect of clinical education. Furthermore, [37] stated that students take evaluations much more seriously than educators do. These results were incongruent with the results of the present study that indicated that evaluation was perceived as the lowest characteristic of clinical instructor. In addition, the results of $[38,39,40]$ showed that nursing competence was perceived by teachers and students as most important characteristic of clinical instructor. This result in the same view of $[32,41]$ who concluded that nursing students value clinical instructors' professional competencies as the most important characteristic.

The personality of a clinical teacher plays an important role in the learning process. Exposing students to excellent role models inspires them to study better. According to [42] the personality of a teacher can have a strong effect on the behavior and attitude of his students. Also, in a study done by $[43,28]$ their results noted that characteristics relating to personal attributes of clinical instructors are highest in overall ratings. These results were inconsistent with the result of the present study that revealed personality traits of the clinical instructor as the lowest valued characteristic an effective clinical instructor by nursing students and clinical instructors.
The results of the present study indicated that undergraduate nursing students and clinical instructors differed in the order of importance of the characteristics of effective clinical instructors. Among the top 10 characteristics of an effective clinical instructor, only three were similar for both groups: a clinical assignment relate to course objectives (TA), stimulates students' interest in the subject (TA), and demonstrates a willingness to help (NC). Faculty and students perceived that clinical instructors are effective when their clinical assignment relate to course objectives, have the ability to stimulate students' interest in the subject and demonstrate a willingness to help.

As regards to the most ten important clinical teaching characteristics of an effective clinical instructor as perceived by undergraduate nursing students, the majority of nursing students perceived demonstrating flexibility in dealing with students, questioning students to elicit understanding, demonstrating a willingness to help and allowing students an opportunity to practice as an important characteristic of an effective clinical instructor. This result is supported by the study result of $[44,45]$ who found that, the nursing students thought that the clinical instructor should ask questions to check student understanding, should be flexible, helpful and provide students an opportunity to practice learning.

Also, nursing students perceive the ability of clinical instructor to communicate knowledge to them as an important characteristic of an effective clinical instructor. This finding is in alignment with the finding of $[12,16]$ who stated that communicative characteristic perceived by nursing students as one of the features of an effective clinical instructor and the teacher should be informative and should be able to impart knowledge to the students in such a manner that will help the students to perform better in real practical situation. Furthermore, the findings of the present study showed that nursing students perceived making continuous evaluation as an important characteristic of an effective clinical instructor. This is in agreement with the findings of [18] that showed student evaluation procedures are considered to be more important by the nursing students.

Among the most ten important characteristics of an effective clinical instructor, only seven out of ten were perceived differently by clinical instructors as an important characteristics of an effective clinical instructor as follows: Helps students identify and make use of practice opportunities, demonstrates open and honest communication with students, presents a neat appearance, provides appropriate and timely feedback, encourage active participation in group discussion, is organized, demonstrates a willingness to help and gives credit for a job well done. From researchers' point of view, this difference may results from the importance given by instructors because they see themselves as a role model to nursing students and they should act like that.

As well in accordance with this result, the study of [46] entitled (effective radiography clinical instructor characteristics) which results showed that clinical instructors valued the ability of the clinical teacher to provide appropriate and timely 
feedback to students, encourage students participation in the discussion and help students to identify and make use of practice opportunities as the most important teaching ability characteristics of an effective clinical instructor.

\section{Conclusion}

The findings of the present study concluded that clinical teaching ability and interpersonal relationships were the most important characteristic of an effective clinical instructor as perceived by the both the undergraduate nursing students and clinical instructors. Furthermore, the results declared that nursing competence, personality traits and evaluation perceived as the lowest characteristics of an effective clinical instructor by both the undergraduate nursing students and clinical instructors. In relation to the top ten characteristics of an effective clinical instructor, only three were similar for both of them: a clinical assignment relate to course objectives (TA), stimulates students' interest in the subject (TA), and demonstrates a willingness to help (NC). This information can be used to provide a foundation in creating a class to educate nurse educators in ways of becoming a more effective clinical instructor.

\section{Recommendations}

Based on the findings of the present study, the following can be recommended that:

- The results may be utilized to improve faculty awareness of students' perceptions on the characteristics of an effective clinical instructor.

- Workshops/seminars should be organized to orient clinical teachers on their roles in clinical setting.

- The study should be replicated in a larger population in different faculties and universities. ex. governmental and private universities.

- Periodic clinical instructors' evaluation is necessary to incorporate unused behaviors, into their practice.

- Clinical instructors should use the NCTEI as a selfassessment to help them in incorporating behaviors that didn't not previously used into their practice.

- Further studies should be conducted to investigate how the personal characteristics of participants as gender and age can affect the perceptions of nursing students and clinical instructors.

\section{References}

[1] Eta, V. Atanga, M. Atashili, J. \& D’Cruz, G. (2011): Nurses and challenges faced as clinical educators: a survey of a group of nurses in Cameroon. Pan African Medical Journal, 8(1). 28.

[2] Pollard, C. Ellis, L. Stringer, E. \& Cockayne, D. (2007): Clinical education: a review of the literature. Nurse Education in Practice, 7(5), 315-322.

[3] Jouybari, L. \& Sangou, A. (2009): An Effective Investigator: A Deep Look At Students and Instructors' Experiences and Perspectives. Dev Med Educ. 6(2):119-28.
[4] Heshmati-Nabavi, F. \& Vanaki, Z. (2010): Professional approach: The key feature of effective clinical educator in Iran. Nurse Education Today, 30(2), 163-168.

[5] Irby, D. (2007): Effective clinical teaching and learning: Clinical teaching and the clinical teacher.

[6] Buchel, T. \& Edwards, F. (2005): Characteristics of effective clinical teachers. Fam Med, 37(1), 30-35.

[7] Lewin, D. (2007): Clinical learning environment for student nurses: Key indices from two studies compared over a 25 year period, Nurse Education Practice, 7; 238-246.

[8] Okoronkwo,I. Onyia, J. Agbo, M. and Okpala, P. (2013): Students Perception of Clinical Teaching and Teacher Behaviors. Open Journal of Nursing. 3(1). 63-70.

[9] Steves, A. (2005): Improving the clinical instruction of student technologists. Journal of nuclear medicine technology, 33(4), 205-209.

[10] Ali, W. (2012): Caring and Teaching Behavior of Clinical Nursing Instructor in Clinical Area as Perceived by their Students. Journal of Education and Practice. 3(7), 15-26.

[11] Niederriter, J. Thoman, J. and Eyth, D. (2013): Nursing Students Perceptions on Characteristics of an Effective Clinical Instructor. http://hdl.handle.net.

[12] Pazandeh, f. Abediyan, K. Jan nesari, S. \& Alavi Majd, H. (2006): Study of the characteristics of an effective clinical instructor from nursing and midwifery students' point of view of Tehran Medical University. The journal of Nursing and midwifery shahid Beheshti University, 5, 46 - 53.

[13] Pournamdar, Z. (2015): Study of Characteristics of an effective clinical instructor from nursing students' point of view in Zahedan. 7(5), 9-13.

[14] Lauber, C. Toth, P. Leary, P. Martin, R. \& Killian, C. (2003): Program directors' and clinical instructors' perceptions of important clinical-instructor behavior categories in the delivery of athletic training clinical instruction. Journal of athletic training, 38(4), 336 .

[15] Alahmadi, F. (2015): Perceptions of Clinical Instructors and Respiratory Therapy Students on Effective Teaching Characteristics of Clinical Instructors in Saudi Arabian Universities. ScholarWorks @ Georgia State University.

[16] Alavi, M. \& Abedi, H. (2007): Experiences and perception of nursing students from the concept of an effective instructor in Clinical teaching. Iranian Journal of Education in Medical Science, 325-334.

[17] Salmani, N. \& Amiriyan, H. (2006): Comparison of students and instructors' point of view of Azad Islamic University of Yazd, about the situation of clinical teaching atmosphere. Steps of development in Medical teaching, 3, 11-18.

[18] Moscaritolo, L. (2009): Interventional strategies to decrease nursing student anxiety in the clinical learning environment. Journal of nursing education, 48(1), 17-23.

[19] Kelly, C. (2007): Students' perceptions of effective clinical teaching revisited. Nurse Education Today, 27, 885- 892. doi:10.1016/j.nedt.2006.12.005.

[20] Phelps, L. (2009): Effective Characteristics of Clinical Instructors. Master thesis. Ball State University. School of Nursing. Muncie, India. 
[21] Chiang, H. (2005): Students' perceptions of effective and ineffective clinical instructors. Journal of Nursing Education, 44(4), 187-192.

[22] Rehan, S. and Barolia, R. (2007): Characteristics of Clinical Faculty Perceived by Nursing Students and Alumni in Karachi. Canadian Journal of Pure and Applied Sciences. 1(1). 35-44.

[23] Sabog, R. Caranto, L. \& David, J. (2015): Effective Characteristics of a Clinical Instructor as Perceived by BSU Student Nurses. International Journal of Nursing Science, 5(1), 5-19.

[24] Knox, J. \& Mogan, J. (1985): Important clinical teacher behaviors as perceived by university nursing faculty, students and graduates. Journal of advanced nursing, 10(1), 25-30.

[25] Wolf, Z. Bender, P. Beitz, J. Wieland, D. \& Vito, K. (2004): Strengths and weaknesses of faculty teaching performance reported by undergraduate and graduate nursing students: A descriptive study. Journal of Professional Nursing, 20 (2), 118-128.

[26] Elcigil, A. \& Sari, H. (2008): Students' opinions about and expectations of effective nursing clinical mentors. Journal of Nursing Education, 47(3), 118-123.

[27] Lee, W. Cholowski, K. \& Williams, A. (2002): Nursing students' and clinical educators' perceptions of characteristics of effective clinical educators in an Australian university school of nursing. Journal of Advanced Nursing, 39(5), 412420 .

[28] Knox, J. \& Mogan, J. (1987): Characteristics of 'best' and 'worst' clinical teachers as perceived by university nursing faculty and students. Journal of Advanced Nursing, 12(3), 331-337.

[29] Prabha, D. Bharti,V. Ponchitra, R. Divya, K. and Singh, S. (2016): Perceptions Of Nursing Students On Clinical Teaching Behaviors Of Teaching Faculty: Correlational Survey Design. Journal of Nursing and Health Science. 5(5). 37-41.

[30] Beitz, J. and Wieland, D. (2005): Analyzing the teaching effectiveness of nursing faculty of full and part time generic BSN, and RNBs nursing students, Jour. of Professional Nursing, 21(1); 32-45.

[31] Papp. I. Markanken, M. and Von-Bonsdroff, M. (2003): Clinical environment as a learning environment: Student nurses' perceptions concerning clinical learning experiences. Nursing Education Today, Volume 23, pp.262-268.

[32] Girija, et al. (2013): Undergraduate Nursing Students' Perception of Effective Clinical Instructor: Oman. International Journal of Nursing Science, Volume 3, Issue 2, pp. 38-44.

[33] Baker, K. (2012): Senior Nursing Students' Perception of Clinical Teacher Behavior. A thesis submitted to the faculty of Gardner-Webb University School of Nursing in partial fulfillment of the requirements for the Degree of Master of Science in Nursing.

[34] Tang, F. Chou, S. \& Chiang, H. (2005): Students perceptions of effective and ineffective clinical instructors. Journal of Nursing Education, 44(4) 187-192 Retrieved November 10,
2008, from CINAHL with Full text.

[35] Clawson Roe, D. (2009): The relationship between prelicensure baccalaureate nursing students' stress and their perceptions of clinical nurse educator caring. ProQuest Dissertations \& Theses: Full Text Database. (UMI No. 3351570).

[36] Elcigil, A. and Hatice, Y. (2006): Determining problems experienced by student nurses in their work with clinical educators in Turkey, Journal of Nursing Education Today, doi.10.1016/J.nedt.2006.08.011.

[37] Brookfield, S. (2006): The skillful teacher (2nd ed.). San Francisco: Jossey-Bass. Cillford. C. (1999). The clinical role of the nurse teacher: A conceptual frame work, Jour Advan. Nurs; 30 (1); 197-205.

[38] Johnson, K. Aasgaard, H. Wahl, A. \& Salminen, L. (2002): Nurse educator competence: A study of Norwegian nurse educators" opinions of the importance and application of different nurse educator competence domains. Journal of Nursing Education, 41(7), 295-301.

[39] Retrieved January 3, 2009, from ProQuest. Nursing \& Allied Health Source database.

[40] Zane, R. Pamela, J. Janice M. Diane M. and Kathleen, O. (2004): Strengths and weaknesses of faculty teaching performance reported by undergraduate and graduate nursing students: A descriptive study. Journal of Professional Nursing, 20, pp. 118-128.

[41] Claudette, K. (2007): Student's perception on effective clinical teaching revisited. Nurse Education Today, 27 (8), pp.885892.

[42] Indra,V. Khan,A. Al Harbi, A. and Al Shammari, R. (2016): Effective Clinical Teaching Behaviors as Perceived by Students and Faculty of College of Nursing in University of Hail, Kingdom of Saudi Arabia. International Journal of Advances in Nursing Management 4(3).235-240.

[43] Gillespie, M. (2002): Student-teacher connection in clinical nursing education. Journal of Advanced Nursing, 37, 566-576. doi:10.1046/j.1365-2648.2002.02131.

[44] Ali, N. and Phelps, L. (2009): Effective Characteristics of Clinical Instructors, Ball State University, Muncie, Indiana, Retrieved December 10, 2014 from https://cardinalscholar.bsu.edu/bitstream/handle.

[45] Hayajneh, F. (2011): Role model clinical instructor as perceived by Jordanian nursing students. Journal of Research in Nursing. 16: 23. The online version of this article can be found at: http://jrn.sagepub.com/content/16/1/23.

[46] Nelson, N. (2011): Beginning Nursing Students Perceptions of the Effective Characteristics and Caring Behaviors of the Clinical Instructors. Dissertation Presented in Partial Fulfillment of the Requirements for the Degree of.Doctor of Philosophy. Capella University.

[47] Ingrassia, J. (2011): Effective Radiography Clinical Instructor Characteristics. Radiologic Technology, 82(5), 409-420. 